\title{
A Comparative Study of Continuous Versus Interrupted Suturing of Episiotomy
}

\author{
Alka Garg'1, Navneet Garg'2, Manish Agrawal', Nikita Garg ${ }^{4}$ \\ ${ }^{1}$ Associate Professor, Department of Obst. \& Gynecology, Rama Medical College, Hapur, ${ }^{2}$ Professor, Department \\ of Surgery, Rama Medical College, Hapur, ${ }^{3}$ Professor\& Head, Department of Paediatrics, Saraswathi Medical

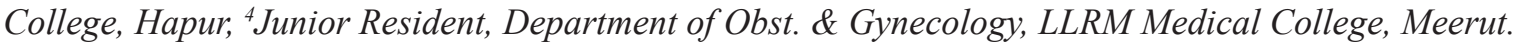

\begin{abstract}
The role of convention repair of episiotomy has come under scrutiny in recent years. This procedure has now been modified from interrupted suturing earlier to continuous stitching of episiotomy.

Aim \&objectives :-This study was done to evaluate the patient comfort \& post-op complications between conventional repair \& continuous repair of episiotomy .

Methodology:-This prospective study was conducted in the department of Gyne \& obstr of Rama medical college, Hapur from July 2018 to June 2019 on 200 patients who were randomly divided into two groups of 100 patients each. In Group A (study group), episiotomy repair was performed by continuous stitching \& group B underwent conventional interrupted suturing repair. Post operatively the efficacy of both procedures analysed on the basis of outcome in form of pain \& other complications.
\end{abstract}

Result :- Majority of patients of episiotomy were in age group of 18 to 26 years. Mean gestational period was $38.4+0.6 \& 38.4+0.5$ for the study \& control group. The mean suturing time was also significantly shorter for study group.Pain score was significantly less after $48 \mathrm{hrs}$. Resumption of sexual activity was significantly shorter in study group.

Conclusion :- The success rate was significantly better in continuous repair group in the form of less procedure time, suture material, postpartum pain \& early resumption of sexual activity.

Keywords :- Episiotomy repair, continuous suturing, interrupted suturing.

\section{Introduction}

Perineal tear is one aspect of childbirth that affects literally millions of women through out the world and can result in long term maternal morbidity. Approximately $85 \%$ of woman will sustain some degree of perineal trauma during vaginal birth and of these, $60-70 \%$ will

\footnotetext{
Corresponding Author:

Dr. Navneet Garg

Professor, Department of Surgery

Rama Medical College Hapur.

Email: gargnavneet13@gmail.com
}

require stitches. ${ }^{1,2,3}$

Spontaneous tears are graded as first degree (involving the perineal skin only), second degree (involving the perineal muscles and skin only), third degree (injury to the anal sphincter complex) and fourth degree (injury to the perineum involving the anal sphincter complex and anal epithelium). ${ }^{4}$ The majority of women experience some short - term discomfort or pain following perineal repair, and up to $20 \%$ will continue to have long - term problems such as superficial dyspareunia (painful intercourse). ${ }^{5}$ Short - and long term maternal morbidity associated with perineal repair 
can lead to major physical, psychological and social problems, affecting the women 's ability to care for her new baby and other members of the family. ${ }^{6}$

\section{Aims \& Objectives}

To evaluate continuous versus traditional ( interrupted muscle and skin ) stitching of episiotomy for the following:

1. Personal comfort and short term maternal morbidity at 48 hours, 1 week and 6 week.

2. Time taken for repair.

3. Amount of suture material required.

4. Dyspareunia or other problems - upto 3 months.

5. Cosmetic results.

\section{Material \& Method}

Place: Department of obstetrics and Gynaecology of Rama Medical college, Hapur.

Duration: The study was carried over a period of 1 year from July 2018 to June 2019.

Study design: Blocked randomization was done. Total 200 cases were divided into two groupswith 100 women in each group. One group of women (study group) had their episiotomy repaired with continuous all layers, and the other group (control group) with conventional method. Suture used was vicrylrapide 1 0 in both the groups.

\section{Inclusion Criteria:}

All primiparous and multiparous women willing to participate in the study, who qualified after exclusion criteria.

\section{Exclusion Criteria:}

1. Episiotomy with extension.

2. Not willing to participate in the study.

3. Gestation age $\leq 36$ weeks.

4. Presentation other than vertex.

5. Prolong repture of membrane (12 hours or more).

6. Dai handled case.

7. $\mathrm{Hb} \% \leq 7 \mathrm{gm} \%$

8. Any Medical disease like diabetes, liver disease , heart disease.

\section{Methodology}

Perineal trauma is traditionally repaired in three stages .First a continuous 'non-locking' stitch is inserted to close the vaginal mucosa commencing at the apex of the wound and finishing at the level of the fourchette with a loop knot.Next the deep and superficial muscles are re-approximated with three or four interrupted sutures and finally, the perineal skin is closed by inserting interrupted mattress sutures.

Type of episiotomy was mediolateral and repair was performed under LA with $2 \%$ xylocaine infiltration . The indication of episiotomy, time taken for stitching and the amount of suture material required were noted. Total 200 cases were equally divided in two groups randomly- Study group (Continous stitching) \& control group (interrupted stitching).

After delivery all cases were kept in the labor room for observation for 1 hour during which their vitals , bleeding PV, uterine condition were watched and episiotomy was inspected before shifting to ward.

Broad spectrum oral antibiotics along with Ibuprofen $400 \mathrm{mg}$ thrice daily were prescribed for 3 days.

In the ward apart from her usual postnatal care, the episiotomy was inspected twice a day for any edema, discharge, hematoma or signs of infection .She was specially asked for any undue discomfort, pain not relieved by the already prescribed analgesics or any other complaints and pain score noted. The patients were discharged at 48 hours or later according to their convenience.

Patients were asked to come for assessment at the end of 1 week and 6 weeks or at any other time in case of a problem .If they could not come due to any reason the telephone assessment was done. All participants were asked about their satisfaction with the procedure. 
Pain Scoring ${ }^{7}$

1. Grade 0 - Patient generally comfortable , minimal pain / discomfort, does not mention about pain.

2. Grade 1 - Patient complains but no added analgesia required and no interference with day to day activity .

3. Grade 2 - Persistent pain interfering with day to day activity .

4. Grade 3 - Severe pain requiring urgent intervention .

\section{Analysis of results}

All women were observed for -

\section{A. UPTO 48 HOURS}

1. Short term pain ( pain score $0-3$ )

2. Analgesia use

3. Local infection

B. At 1 WEEK
1. Pain

2. Local infection

3. Need for Resuturing

4. Any other complication

C. At 6 WEEKS

1. Long term pain

2. Any other complication

D. At 3 MONTHS

1. Dyspareunia / pain

2. Resumption of painfree intercourse

3. Any other complication

\section{Obervations and Results}

Out of 200 women enrolled initially, due to loss in follow up or no telephonic response, the study group had $\mathrm{N}=84$ while the control group had $\mathrm{N}=79$ patients . The following analysis is based on the final set of patients on whom detailed reporting was performed .

Table 1: Age, Gestation age, Hb\& Baby weight distribution

\begin{tabular}{|l|l|l|l|}
\hline \multicolumn{2}{|l|}{ Factors } & $\begin{array}{l}\text { Study Group- Continuous } \\
\text { Suturing }\end{array}$ & $\begin{array}{l}\text { Control Group- Interrupted } \\
\text { Suturing }\end{array}$ \\
\hline \multirow{4}{*}{ Age (years) } & Mean & 22.46 & 21.95 \\
\cline { 2 - 5 } & Minimum & 18.00 & 18.00 \\
\cline { 2 - 5 } & Maximum & 26.00 & 26.00 \\
\cline { 2 - 5 } & Standard Deviation & 1.91 & 1.72 \\
\hline \multirow{5}{*}{ Gestational Age (weeks) } & Mean & 38.39 & 38.39 \\
\cline { 2 - 5 } & Minimum & 37.00 & 37.00 \\
\cline { 2 - 5 } & Maximum & 39.30 & 39.50 \\
\cline { 2 - 5 } & Standard Deviation & 0.62 & 0.55 \\
\hline
\end{tabular}


Cont... Table 1: Age, Gestation age, Hb\& Baby weight distribution

\begin{tabular}{|l|l|l|l|}
\hline \multirow{5}{*}{$\mathrm{Hb}(\mathrm{gm} / \mathrm{dl})$} & Mean & 8.69 & 8.80 \\
\cline { 2 - 5 } & Minimum & 8.00 & 8.00 \\
\cline { 2 - 5 } & Maximum & 11.00 & 11.00 \\
\cline { 2 - 5 } Baby Weight $(\mathrm{Kg})$ & Standard Deviation & 0.52 & 0.60 \\
\hline \multirow{3}{*}{} & Mean & 2.64 & 2.67 \\
\cline { 2 - 5 } & Minimum & 0.60 & 0.60 \\
\cline { 2 - 4 } & Maximum & 3.20 & 3.40 \\
\cline { 2 - 4 } & Standard Deviation & 0.30 & 0.30 \\
\hline
\end{tabular}

Majority of cases in both the groups were between 18 and 26 years of age. The mean gestation period was $38.4 \pm 0.6$ and $38.4 \pm 0.5$ weeks, haemoglobin levels $8.7 \pm 0.5 \& 8.8 \pm 0.6 \mathrm{gm} \%$ and baby weight varied between $2.6 \pm 0.3$ and $2.7 \pm 0.3 \mathrm{Kg}$ for the study \& control group respectively.

Suturing time: The mean suturing time was significantly shorter for study group $7.2+\ldots 1.2$ minutes vs 12.8+_ 1.1 minutes for the control group.

Amount of Suture Material Required: The mean amount of suture material required was significantly less in study group $1 \pm 0$ vs $1.3 \pm 0.4$ for control group.

\section{Pain Scoring}

As no pain activity was observed at the end of week 1 and week 6 in both the control and study groups, we analysed the pain scoring after 48 hours only. The $\mathrm{T}-$ Test suggested that mean of the study group $0.1+0.2$ was significantly different from that control group 0.2+0.4.(P- value 0.006)

Table 2: Pain Score Comparison

\begin{tabular}{|l|l|l|l|}
\hline \multirow{2}{*}{ Pain Scoring (No. of Patients) } & $\begin{array}{l}\text { Study Group- Continuous } \\
\text { Suturing }\end{array}$ & $\begin{array}{l}\text { Control Group- Interrupted } \\
\text { Suturing }\end{array}$ \\
\hline \multirow{4}{*}{ After 48 hours } & 0 & 79 & 63 \\
\cline { 2 - 4 } & 1 & 5 & 16 \\
\cline { 2 - 5 } & 2 & 0 & 0 \\
\cline { 2 - 5 } & 3 & 0 & 0 \\
\hline \multirow{3}{*}{ After 1 Week } & & 84 & 79 \\
\cline { 2 - 5 } & 0 & 0 & 0 \\
\cline { 2 - 5 } & 1 & 0 & 0 \\
\cline { 2 - 5 } & 2 & 0 & \\
\hline
\end{tabular}


Cont... Table 2: Pain Score Comparison

\begin{tabular}{|l|l|l|l|}
\hline & & & \\
\hline \multirow{4}{*}{ After 6 Weeks } & 0 & 84 & 79 \\
\cline { 2 - 5 } & 1 & 0 & 0 \\
\cline { 2 - 5 } & 2 & 0 & 0 \\
\cline { 2 - 5 } & 3 & 0 & 0 \\
\hline & & & \\
\hline
\end{tabular}

\section{Resumption of sexual Activity}

The mean resumption of sexual activity was meaningfully shorter for the study group $44.5 \pm 2.2$ days vs. $50.5 \pm 2.7$ days for the control group ( $\mathrm{P} \leq 0.001)$.

Table 3: Post-operative complications

\begin{tabular}{|l|l|l|}
\hline Complications & Study Group- Continuous Suturing & Control Group- Interrupted Suturing \\
\hline Hematoma & $0 / 84$ & $0 / 79$ \\
\hline Need for Re- Suturing & $0 / 84$ & $0 / 79$ \\
\hline Need for Removal of Suture Material & $0 / 84$ & $0 / 79$ \\
\hline Any other Complication & $0 / 84$ & $0 / 79$ \\
\hline
\end{tabular}

There were no post-operative complications in the either study group (Continuous suturing )or control group (Interrupted suturing ).

\section{Discussion}

Women reported low levels of perineal pain after repair with the continuous technique compared to those repaired with more traditional interrupted suturing methods.The difference in pain between the two techniques may be due to increased suture tension caused by edema in the perineal tissue. It is very easy to over tighten locked or interrupted stitches, which may restrict the distribution of tissue edema and cause increased pain. With the continuous technique, the tension is transferred throughout whole length of a single suture; also the skin sutures are inserted well below the skin surface, thus avoiding the nerve endings. Moreover, good cosmetic result were reported at six weeks following childbirth. ${ }^{8}$
Recent researches have reported that the use of a more rapidly absorbed form of polyglactin 910 suture material (Vicry LRapide ; ethicon ) is associated with a significant reduction in suture removal when compared to standard absorbable suture materials ${ }^{9,10}$.

In the present study, the mean suturing time was significantly shorter for the study group $7.2 \pm 1.2 \mathrm{~min}$ vs.12.8 \pm 1.1 minutes for the control group. Similar observation was reported by Klein MC and Schulz KF. 9,10

The study group used a single suture to carry forward the continuous method the mean and standard deviation were at $1 \pm 0$ respectively. However, the control group 
was $1.3 \pm 0.4(\mathrm{P}-\text { value } \leq 0.001)^{9,10}$. As no pain activity was observed in both the groups. We analysed the pain scoring after 48 hours and at 1 and 6 week. The mean resumption of sexual activity was significantly shorter for the study group $44.5 \pm 2.2$ days vs $50.5 \pm 2.7$ days, for the control group. Same conclusions were drawn by Sleep J, Asheim V an Marty N in their studies. ${ }^{11,12,13}$

\section{Conclusion}

The conclusions drawn from the study are that continuous suturing is faster, requires less suture material, less postpartum pain with less dyspareuniain comparison to traditional repair. Hence continuous stitching of episiotomy is recommended for clean uncomplicated cases to cut time and cost of episiotomy.

\section{Financial Support: Nil}

\section{Conflict of Interest: None}

Ethical Clearance: Was taken from Institutional Ethical Committee and informed written consent was obtained from the participating patients.

\section{References}

1. Arulkumaran S, George E, Margan, Onnig Tamizian Oxford Hand Book of Obstetrics and Gynecology. 2004; 31:3 22-324.

2. McCandlish R, Bowler U, van Asten H, Berridge G, Winter C, Sames L, et al. A randomized controlled trial of care of the perineum during second stage of normal labor. Br J Obstet Gynaecol. 1998; 105:12621272.

3. Sleep J, Grant A, Garcia J, Elbourne D, Spencer J, Chalmers I. West Berkshire Perineal management trial. British Medical Journal 1984; 289: 587-90.

4. Klein MC, Gauthier RJ, Robbins JM, KaczorowskiJ, Jorgensen SH, Franco ED, et. Relationship of episiotomy to perineal American Journal of Obstetrics and Gynecology 1994; 171:591-8.
5. Glazener CMA. Sexual function after childbirth: women's experiences. persistent morbidity and lack of professional recognition, British Journal of Obstetrics and Gynaecology 1997;104:330-5.

6. Thacker SB, Banta HD. Benefits and risks of episiotomy: an interpretive review of the English language literature, 1860-1980. ObstetGynecolSurv 1983;322-338.

7. Andrew v, Thakar R, Sultan AH. Evaluation of port partam penineal pain \& dispareunia-A prospective study. E.ur, J Obst. Gynecol reprod Biol 2008: 137:152-6.

8. Rockner G, Olund A. The use of episiotomy in primiparas in Sweden: a descriptive study with particular focus on two hospitals. ActaObstetGynecolScand 1991; 70:325-330.

9. Klein MC, Gauthier RJ, Robbins JM, et al. Relationship of episiotomy to perineal trauma and morbidity, sexual dysfunction, and pelvic floor relaxation. Am J ObstetGynecol 1994; 171:591598.

10. Schulz KF, Chalmers I, Grimes DA, Altman DG. Assessing the quality of randomization from reports of controlled trials published in obstetrics and gynecology journals. JAMA 1994; 272:125128.

11. Sleep J, Grant A, Garcia J, Elbourne D, Spencer J, Chalmers I. West Berkshire perineal management trial. BMJ 1984 1984; 289:587-590.

12. Asheim V, et al, cochrane Database system Rev2017 Perineal techniques during the second stage of labour for reducing perineal trauma.

13. Marty N, et al, Gynecol obstet Fetil Senol. 2018. Perineal tears \& episiotomy-Surgical procedureCNGOF perineal prevention \& protection in obstetrics guidelines. 